\title{
Erratum to: Separation and Characterization of Epithelial and Mesenchymal-like Murine Mammary Tumor Cells Reveals Epithelial Cell Differentiation Plasticity and Enhanced Tumorigenicity of Epithelial-enriched Tumor Cells
}

\author{
Katie A. Palen ${ }^{1,2}$ • Weiqing Jing ${ }^{1,2}$ - James J. Weber ${ }^{1,2}$ - Sara B. Tilkens ${ }^{1,2}$ • \\ Andrew M. Chan ${ }^{1,2} \cdot$ Bryon D. Johnson ${ }^{1,2}$ • Jill A. Gershan ${ }^{1,2}$
}

Published online: 8 January 2016

(C) Springer Science+Business Media Dordrecht 2016

\section{Erratum to: Cancer Microenvironment}

DOI 10.1007/s12307-011-0095-2

The acknowledgement text of the published online article should have included "Supported in part by the Institutional Research Grant \#IRG-86-004-26 from the American Cancer Society".

The complete Acknowledgement text should be:

Acknowledgments Support for this work was provided by the Kathy Duffey Fogarty Greater Milwaukee Foundation, the Midwest Athletes Against Childhood Cancer (MACC) Fund, and the Cedarburg Junior Woman's Club. Supported in part by the Institutional Research Grant \#IRG-86-004-26 from the American Cancer Society. We thank Elizabeth Jaffe for supplying the NT tumor cell line and Michael Dwinell for supplying the MDA MB 231 and MCF7 cell lines. We also thank Alexander Liska, Katie McShane and Rachel Wilkinson for technical support.

The online version of the original article can be found at http://dx.doi.org/ 10.1007/s12307-011-0095-2.

Jill A. Gershan

jgershan@mcw.edu

Katie A. Palen

kpalen@mcw.edu

Weiqing Jing

wjing@mcw.edu

James J. Weber

jweber@mcw.edu

Sara B. Tilkens

stilkens@mcw.edu
Andrew M. Chan

axchan@mcw.edu

Bryon D. Johnson

bjohnson@mcw.edu

Department of Pediatrics, Section of Hematology-Oncology, Medical College of Wisconsin, 8701 Watertown Plank Road, Milwaukee, WI 53226, USA

2 The Children's Research Institute, Children's Hospital of Wisconsin, Milwaukee, WI 53226, USA 